\title{
Formação docente em tempos de pandemia da COVID-19: um relato do Recôncavo da Bahia
}

\author{
Eniel do Espírito Santo ${ }^{1}$ \\ Adilson Gomes dos Santos ${ }^{2}$
}

\section{RESUMO}

A pandemia da COVID-19 arremessou tempestivamente professores para os ambientes virtuais, demandando formação docente para a sua atuação on-line. Neste estudo, analisamos a concepção e implementação do programa de formação em tecnologias digitais da Universidade Federal do Recôncavo da Bahia (UFRB), refletindo tanto acerca desse processo inicial como dos principais fundamentos da formação docente para as tecnologias digitais. Com abordagem metodológica da pesquisa-formação, relata-se a experiência do programa formativo, com cursos que alcançaram 30,1\% dos docentes da UFRB e webinários com 2.100 participantes. Concluiu-se que o programa formativo forneceu subsídios para os professores na sua atuação no Ensino On-line, apontando-lhes caminhos para o aprimoramento de suas competências digitais.

Palavras-chave: Formação Continuada Docente. Tecnologias Digitais. COVID-19.

\footnotetext{
${ }^{1}$ eniel@ufrb.edu.br - Universidade Federal do Recôncavo da Bahia - UFRB

2 adilsongomes@ufrb.edu.br - Universidade Federal do Recôncavo da Bahia - UFRB
} 


\section{Professors continuing education in COVID-19 pandemic times: a report from Bahia's Reconcavo}

\section{ABSTRACT}

The COVID-19 pandemic promptly hurled professors into virtual environments, demanding professors continue education for their online performance. In this study, we analyze the design and implementation of the digital technologies in the professor continuing education program at the Federal University of Bahia's Reconcavo (UFRB). We reflect both in its design and implementation, as well as in the main framework of professor continuing education for digital technologies. With a methodological approach to education-research, the experience of the continuing education program is reported, with courses that reached $30.1 \%$ of UFRB professors and webinars with 2,100 participants. We conclude that the continuing education program provided subsidies for professors in their performance in online teaching, pointing out ways to improve their digital competencies.

Keywords: Professors continuing education. Digital Technologies. COVID-19. 
Em 2020, a pandemia da COVID-19, doença causada pelo novo coronavírus (SARS-CoV-2), impactou profundamente toda a humanidade, confrontando-a com uma crise sanitária acelerada pela " 1 a onda", que se espalhou por todo o mundo, impondo o isolamento social como principal mecanismo para se tentar barrar a rápida proliferação do vírus. Também foi notória a disseminação das fake news e o "negacionismo" científico de muitos governantes que em nada contribuíram para mitigar o sofrimento dos milhões de infectados e, infelizmente, dos familiares de outros milhares que tiveram sua vida abruptamente ceifada.

Neste contexto sombrio, em especial, com o avanço da pandemia, as instituições de todos os níveis de ensino no Brasil e no mundo não tiveram outra alternativa senão fechar as suas portas. Todo o planejamento pedagógico previsto para ser realizado de modo presencial foi suspenso, interrompendo o semestre letivo que acabara de ser iniciado no país. Como alternativa para continuidade das atividades de ensino, foi adotado o chamado Ensino Remoto Emergencial, ancorado principalmente nas tecnologias digitais e analógicas aplicadas à educação, "velhas conhecidas" na modalidade da Educação a Distância (EaD).

Instaurava-se assim, no dizer de Santos (2020), uma cruel pedagogia do vírus, pois cerca de 29\% dos lares brasileiros não possuíam conexão com banda larga de internet (CETIC.BR, 2020), com a consequente exclusão dos estudantes e ampliação do vergonhoso fosso de desigualdade existente no país. Por outro lado, a pesquisa do Instituto Península (2020) revelou que $86 \%$ dos professores da Educação Básica afirmavam não se sentir preparados para atuação docente nos ambientes virtuais de aprendizagem (AVA), correndo-se o risco de tornar o Ensino On-line uma mera e equivocada transposição didática do presencial para o virtual.

Com esse distópico pano de fundo, as Instituições de Ensino Superior (IES), em especial as Instituições Públicas de Ensino Superior (IPES), tiveram que se debruçar em um planejamento tempestivo a fim de dar continuidade às atividades acadêmicas no ciberespaço, não obstante os sérios problemas estruturais no acesso à internet e disponibilidade de equipamentos para os estudantes em vulnerabilidade econômica, apesar das incipientes políticas públicas de ações afirmativas implementadas.

Dessa forma, neste artigo temos como objetivo analisar os percursos formativos do Programa de Formação em Tecnologias Digitais implementado pela Universidade Federal do Recôncavo da Bahia (UFRB), refletindo criticamente nos seus pontos fortes e oportunidades de melhorias, visando inspirar outras IPES nos seus processos de formação continuada docente. Como objetivos específicos, o estudo discute os principais fundamentos epistêmicos que norteiam a formação docente para as tecnologias digitais, além de apresentar os resultados do programa formativo realizado pela UFRB, sob o olhar dos seus protagonistas.

Do ponto de vista metodológico, este estudo inspira-se na metodologia da pesquisaformação, configurando-se como uma pesquisa descritiva, com abordagem qualitativa, tendo como procedimentos de coleta de dados a revisão bibliográfica e o relato de experiência. O locus da experiência foram as ações do Programa de Formação em Tecnologias Digitais para Comunidade UFRB, realizadas entre os meses de agosto e setembro de 2020, com a sua proposta 
de percursos formativos para o enfrentamento dos desafios pedagógicos diante da implementação do semestre remoto na Universidade Federal do Recôncavo da Bahia.

Este estudo é relevante para a discussão dos programas de tecnologias digitais na formação de professores, especialmente no contexto pandêmico em que se faz urgente a apropriação desse saber pelos docentes de todos os níveis de ensino.

\section{FORMAÇÃO DOCENTE PARA AS TECNOLOGIAS DIGITAIS: UM MOSAICO DE IDEIAS}

A formação docente inicial realizada nos cursos de licenciatura, bem como a formação docente continuada ocorrida ao longo da vida, requerem cuidadosa atenção para se evitar uma rápida obsolescência formativa diante da efêmera modernidade líquida vivenciada neste conturbado século XXI, como já refletia Bauman (2001).

Nos processos de formação docente, não se pode desaperceber a admoestação de Freire (1989, p. 2) ao afirmar de forma enfática que "ninguém começa a ser educador numa certa terçafeira às quatro horas da tarde [...]. A gente se faz educador, a gente se forma, como educador, permanentemente, na prática e na reflexão sobre a prática".

Não restam dúvidas de que professores reflexivos com sólida formação teórica e prática em sua respectiva área de ensino é o que se deveria esperar nesta pandêmica modernidade. Apesar disso, os dados do Observatório Nacional do Plano Nacional da Educação (OPNE, 2020) revelaram a constrangedora face da formação docente inicial no Brasil ao apontar que, em 2019, apenas $56,8 \%$ das turmas dos anos finais do Ensino Fundamental possuíam professores com formação compatível com a disciplina que lecionavam. Além de professores sem formação específica, outro desafio consiste em articular os currículos dos cursos de licenciatura com a Educação Básica, ampliando-se a oferta de programas de formação continuada que possam suprir "as lacunas da formação inicial, possibilitando que os professores mantenham-se atualizados", afirmam Santo e Lima (2020, p. 288).

No âmbito do Ensino Superior, a formação docente inicial e continuada ocorre nos cursos de pós-graduação lato e stricto sensu, sendo que as IES necessitam atender aos indicadores relacionados com a titulação docente instituídos pelo Sistema Nacional de Avaliação do Ensino Superior (SINAES), nos respectivos atos regulatórios de autorização, reconhecimento e renovação do reconhecimento dos cursos de graduação (BRASIL, 2017a; 2017b).

Em todo caso, a formação docente não se restringe tão somente ao domínio dos conteúdos dos componentes curriculares, sendo imprescindivel o desenvolvimento de competências técnicas e pedagógicas relacionadas com o processo de ensino e aprendizagem, pois do contrário corre-se o risco de se promover a famigerada pedagogia bancária, tão severamente criticada por Freire (1996) e incompatível com este pandêmico século XXI.

Nesse sentido, o construto teórico denominado Conhecimento Tecnológico e Pedagógico do Conteúdo, conhecido pelo seu acrônimo TPACK - Technological Pedagogical Contend Knowledge -, fornece importantes pistas. Constitui-se na intersecção de três macrossaberes necessários à prática educativa, isto é, a articulação entre o conhecimento do conteúdo, conhecimento pedagógico e o conhecimento tecnológico - conforme Figura 1. A sobreposição desses conhecimentos pressupõe a representação de conceitos teóricos e práticos, utilizando-se 
as tecnologias digitais, juntamente com técnicas e metodologias pedagógicas para a transposição didática do conteúdo, como apontam Koehler, Mishra e Cain (2013) e Rolando, Luz e Salvador (2015). Deveras, o mapeamento do nível de Conhecimento Tecnológico e Pedagógico do Conteúdo se constitui em um instrumento valioso para o delineamento de programas de formação docente, conforme revelam os estudos de Cardoso e Santo (2020).

Figura 1: Conhecimento Tecnológico e Pedagógico do Conteúdo (TPACK)

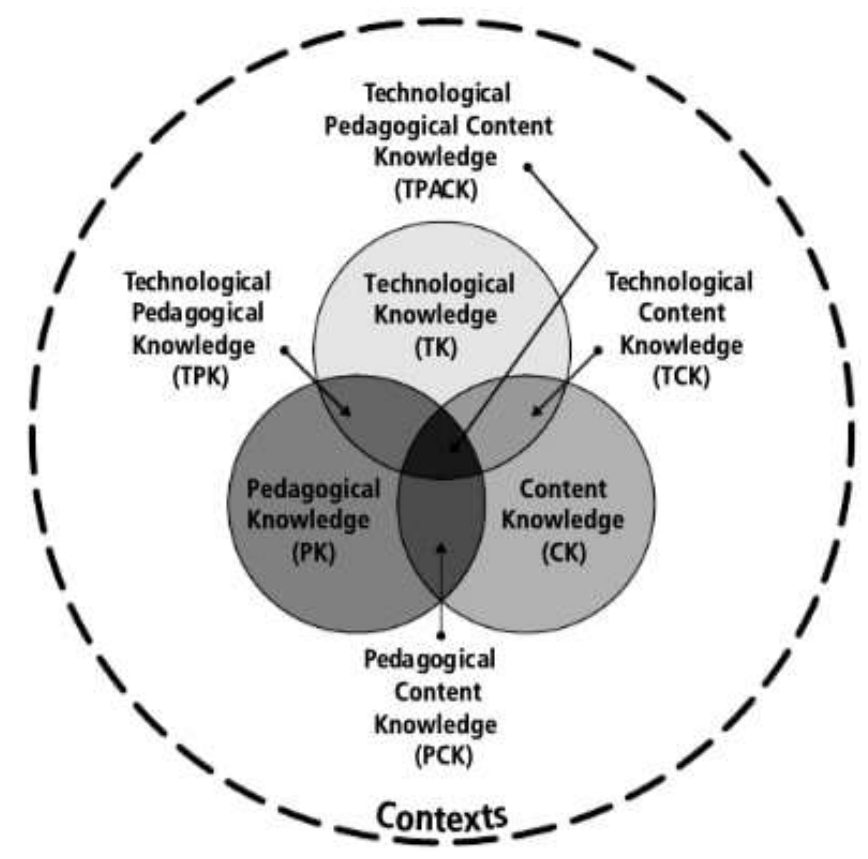

Fonte: Koehler, Mishra e Cain (2013).

Indubitavelmente, a formação docente neste turbulento séculoXXI não pode prescindir das tecnologias digitais, pois professores e estudantes estão imersos em uma cultura digital amplamente enriquecida pela utilização das tecnologias. Ressaltamos que Prensky $(2001 ; 2012)$ já nos alertava que a atual geração de estudantes é caracterizada por nativos e sábios digitais, que utilizam com propriedade as tecnologias e redes sociais, enquanto que os professores são metaforicamente descritos como imigrantes digitais que estão buscando desenvolver e aperfeiçoar as competências relacionadas com o letramento digital, para dar conta das demandas desta geração hiperconectada de "polergazinhas" e "polegarzinhos", no dizer de Serres (2015). Deveras um desafio sem precedentes!

Ainda assim, mesmo com suas habilidades digitais inquestionáveis, diante da imensidão de informações disponíveis, os estudantes ainda precisam do suporte de seus professores para ajudá-los a "extrair um sentido da informação, perceber a diferença entre o que é importante e o que não é, e, acima de tudo, combinar os muitos fragmentos da informação num amplo quadro de mundo", nos diz Harari (2018, p. 322). Nessa perspectiva, os professores precisam mais do que nunca desenvolver e aprimorar continuamente suas competências digitais, isto é, saber utilizar as tecnologias digitais de informação e comunicação para a "[...] mediação e resolução de problemas oriundos do contexto da sociedade da aprendizagem, possibilitando a transformação, mudança social, política e econômica [...]", nos esclarecem Sales e Moreira (2019, p. 18). 
Percebe-se que não basta tão somente possuir computador ou qualquer dispositivo conectado à banda larga de internet com acesso a uma rede social do momento, pois, no contexto da cibercultura é preciso mais, é imprescindível "saber buscar e tratar a informação em rede, transformar informação em conhecimento, comunicar-se em rede, produzir textos em varias linguagens e suportes [...]", aporta Santos (2019, p. 92).

Não obstante, tais aportes teóricos que indicam a premente necessidade de formação docente para as tecnologias digitais, a crise sanitária resultante da pandemia da COVID-19 encontrou a maior parte dos professores despreparados para atuar nos ambientes virtuais de aprendizagem. Dados do início da pandemia, coletados com professores da Educação Básica pelo Instituto Península (2020), revelaram que além de não se sentirem preparados para o Ensino Online (86\%), a maioria dos professores afirmaram que não tinham recebido nem apoio emocional, tampouco formação para ensinar no formato on-line.

Um dos fatores que contribuem para esse despreparo docente é a formação inicial, pois a maioria dos currículos dos cursos de licenciatura no país "não dedicam carga horária expressiva para o aprendizado dos novos docentes em como se apropriar pedagogicamente das tecnologias", afirmam Silva et al. (2020, p. 22). Infelizmente, somente alguns poucos cursos inserem componentes em suas matrizes curriculares, muitas vezes optativos, relacionados com as tecnologias digitais na educação. Apesar disso, compreende-se que desenvolver competências para saber utilizar as tecnologias digitais não deve se limitar a uma discussão epistêmica em um único componente curricular; as tecnologias necessitam fazer parte integrante das estratégias pedagógicas de todos os componentes curriculares do curso, transformando "a aprendizagem num ato normal do quotidiano, até mesmo fazendo com que esta nem seja sequer reconhecida como sendo aprendizagem", afirmam Trindade e Moreira (2017, p. 55).

No Ensino Superior a formação docente apresenta cenário semelhante, pois embora as IES tenham vivenciado notória expansão da Educação a Distância na última década, a maior parte dos professores ainda apresenta incipiente nível de desenvolvimento de competências digitais para fazer frente às demandas galopantes impostas pelo Ensino On-line, como alternativa à paralisação das aulas presenciais diante da crise sanitária. Os estudos de Dias-Trindade e Santo (2021), Ota e Dias-Trindade (2020) e Dias-Trindade, Moreira e Ferreira (2020) apontam que em diferentes contextos os professores universitários apresentam um nível mediano de competências digitais, enfatizando a necessidade de programas de formação docente continuada em tecnologias digitais para suprir as lacunas apontadas.

Ainda assim, a universidade se constitui em um importante espaço da sociedade para a reflexão, pois como afirma Salles (2020, p. 42), a universidade pública, em especial, não está a serviço apenas dos interesses do mercado "nem pode determinar-se por ele; antes, constitui-se ela própria um privilegiado espaço de sociabilidade, no qual ela revisa seus rituais, refaz-se em novos pesquisadores, performa-se cidadãos". Nesse sentido, é compreensível que no ambiente universitário as mudanças pedagógicas relacionadas com as emergentes tecnologias digitais sejam objeto de reflexão, crítica e contraponto a fim de se evitar tanto a plataformização disseminação de plataformas digitais proprietárias que eventualmente podem utilizar dados privados dos estudantes e professores - quanto a uberização da educação, com a sua respectiva precariedade nas relações trabalhistas docente. Apesar disso, a crise sanitária resultante da 
pandemia impôs o aligeiramento das discussões, arremessando para o ciberespaço educativo as IES públicas e privadas, com seus professores sem formação apropriada para a atuação docente on-line.

Finalmente, sem a pretensão de esgotar a temática neste efervescente campo em construção, ressalta-se o perigo em se implementar a formação docente para as tecnologias com foco tão somente na sua perspectiva instrumental, naquilo que Pesce (2014) denomina como "fetichização da técnica", ou seja, na mera instrumentalização dos professores para a utilização de softwares, aplicativos e plataformas. A autora não desmerece a importância da instrumentalização, todavia destaca que esta não deve constituir o eixo norteador dos processos formativos sem a apropriada reflexão consistente sobre a intencionalidade pedagógica e o contexto político, socioeconômico e cultural em que a instituição e seus estudantes estão inseridos.

\subsection{Procedimentos metodológicos}

Este estudo fundamenta-se na abordagem qualitativa, configurando-se como uma pesquisa exploratória e descritiva, norteada pela metodologia da pesquisa-formação (TRIVIÑOS, 2006; MINAYO, 2006; SANTOS, 2019). Compreende-se que experiências de pesquisa-formação promovem a reflexão dos sujeitos, emergindo registros de narrativas com pesquisadores e pesquisados envolvidos no processo, conforme Santos (2019).

A opção metodológica pela pesquisa-formação reside no fato do papel ativo dos autores como pesquisadores e, concomitantemente, como coordenadores que conduziram todo o processo de formação dos professores. Assim, o campo de pesquisa não se constitui em um espaço privilegiado e apartado, capaz de possibilitar olhar distanciado do fenômeno, antes se trata de um "espaço de formação e autoformação, um espaço de implicação, onde o risco, a incerteza, a desordem serão contemplados sem prejuízo do rigor do fazer ciência”, nas palavras de Santos (2019, p. 102).

Desse modo, neste estudo, a pesquisa-formação está indelevelmente imbricada com a docência, sendo a "educação on-line o contexto, campo de pesquisa e dispositivo formativo" (SANTOS, 2019, p. 20). Isso posto, o locus de experiência da pesquisa-formação foram as ações de formação docente realizadas no âmbito do Programa de Formação em Tecnologias Digitais para a Comunidade UFRB, com a sua proposta de percursos formativos visando ao enfrentamento dos desafios técnicos e pedagógicos para a implementação do semestre remoto na Universidade Federal do Recôncavo da Bahia (UFRB).

O Programa de Formação docente foi implementado entre os meses de agosto e setembro de 2020, consistindo na oferta de seis cursos on-line de curta duração, cinco webinários formativos, além de dois cursos on-line direcionados para os estudantes. Ao término de cada ação formativa, os participantes preencheram um questionário de avaliação da satisfação que, juntamente com os registros nas plataformas digitais utilizadas, forneceram importantes subsídios para as análises e discussões deste estudo. 


\subsection{Análise e discussão}

A Universidade Federal do Recôncavo da Bahia (UFRB) é uma jovem instituição de Ensino Superior pública, criada em 2005 com o desmembramento da Escola de Agronomia da Universidade Federal da Bahia (UFBA). Com sede em Cruz das Almas, possui campi nos municípios de Amargosa, Cachoeira, Feira de Santana, Santo Amaro e Santo Antônio de Jesus, alcançando mais de 13 mil estudantes nos cursos de graduação e pós-graduação lato e stricto sensu (UFRB, 2021a).

Em agosto de 2020, a UFRB contava com um quadro de 899 docentes no magistério superior, sendo que desse total $643(71,5 \%)$ com titulação de doutorado e 209 (23,2\%) com mestrado, perfazendo o percentual de $94,7 \%$ do corpo docente qualificado com titulação stricto sensu em nível de mestrado ou doutorado (UFRB, 2021b).

Não obstante, a elevada qualificação acadêmica do corpo docente da UFRB, a pandemia da COVID-19 encontrou a maior parte dos professores com lacunas para atuação docente no Ensino On-line. Os estudos de Cardoso e Santo (2020, p. 93) demonstravam que em uma amostra de 12,9\% dos docentes UFRB, o nível do Conhecimento Tecnológico e Pedagógico do Conteúdo (TPACK) encontrava-se no patamar moderado, denotando a necessidade de programas de formação continuada "visando o aprimoramento de competências e o desenvolvimento de literacia digital relacionadas com as tecnologias, imbricadas com os conteúdos curriculares e as estratégias pedagógicas utilizadas", apontaram os autores.

Adicionalmente, os estudos de Dias-Trindade e Santo (2021), com uma amostra de 20,1\% de docentes da UFRB, assinalavam que os professores se encontravam no nível 3 - integradores - de competência digital, em uma escala de 1 a 6, mínimo e máximo respectivamente. Tais dados indicavam que o corpo docente não se constituía em um grupo de recém-chegados à aplicação das tecnologias na educação, pois já utilizavam o básico das tecnologias digitais nas suas práticas pedagógicas; todavia, precisavam intensificar a sua formação continuada a fim de ampliar o uso das tecnologias de forma integrada, potencializando o processo de ensino e aprendizagem, constataram os autores.

Por fim, a Pró-reitoria de Graduação (PROGRAD) da UFRB realizou em junho de 2020 uma consulta à comunidade acadêmica - docentes, discentes e técnicos administrativos - da UFRB, a fim de verificar a possibilidade da realização de atividades acadêmicas durante a pandemia. No extrato docente, foram 542 professores que responderam à consulta, sendo que 500 (92,3\%) afirmaram seu interesse em participar de formação na área de tecnologias e Ensino Remoto. Ademais, $411(75,8 \%)$ revelaram que tinham pouca ou nenhuma experiência com a utilização de recursos tecnológicos em práticas pedagógicas on-line, enquanto que $116(21,4 \%)$ apontaram que possuíam média experiência (UFRB, 2020). Tais dados corroboram com os resultados dos estudos realizados por Cardoso e Santo (2020) e Dias-Trindade e Santo (2021).

Consubstanciados pelos dados supracitados que demonstravam a inequívoca necessidade de formação docente para as tecnologias digitais, e, diante da iminência do início do semestre letivo a ser realizado no formato do Ensino On-line, foi desenhado o Programa de Formação em Tecnologias Digitais para a Comunidade UFRB, coordenado pela Superintendência de Educação Aberta e a Distância (SEAD) em articulação com a Pró-reitoria de Pesquisa, Pós-graduação, Criação e Inovação (PPGCI) e a PROGRAD da UFRB. 
O Programa de Formação em Tecnologias Digitais para a Comunidade UFRB foi realizado no formato on-line e composto por percursos formativos independentes, dispostos, como já exposto, em seis cursos e cinco webinários formativos destinados ao corpo docente, além de 2 cursos para os discentes que não farão parte desta análise, visto que não se relacionam com a formação docente.

As temáticas dos percursos formativos consideraram as lacunas nas competências digitais apresentadas pelos estudos de Dias-Trindade e Santo (2021), bem como os tópicos de interesse apontados pela PROGRAD na consulta à comunidade acadêmica (UFRB, 2020).

O Programa de Formação foi registrado na Pró-reitoria de Extensão (PROEXT) da UFRB, sendo os cursos e webinários formativos devidamente certificados como atividade de extensão, conforme os critérios estabelecidos para certificação.

\subsubsection{Percurso formativo dos cursos on-line}

Consoante às necessidades formativas dos professores previamente identificadas, a equipe multidisciplinar da SEAD debruçou-se sobre o design instrucional dos cursos on-line, definindo-se a modelagem educacional que norteou a produção dos cursos - Quadro 1 -, em consonância com as recomendações de Kenski (2019) e com o Modelo Pedagógico Virtual UFRB para o Ensino On-line (CARDOSO et al., 2018).

\section{Quadro 1 - Modelagem dos cursos do Programa de Formação em Tecnologias Digitais UFRB}

\begin{tabular}{|c|c|c|}
\hline Sessão do curso on-line & \multicolumn{2}{|l|}{ Descrição } \\
\hline Ambientação & \multicolumn{2}{|c|}{$\begin{array}{l}\text { - Videoaula com apresentação do curso pelo professor; } \\
\text { - Fórum com autoapresentação dos participantes. }\end{array}$} \\
\hline Orientações gerais & \multicolumn{2}{|c|}{$\begin{array}{l}\text { - Plano de ensino do curso; } \\
\text { - Sistemática de avaliação da aprendizagem; } \\
\text { - Biblioteca virtual; } \\
\text { - Contato com a coordenação; } \\
\text { - Mural de avisos. }\end{array}$} \\
\hline \multirow{6}{*}{ Trilha de aprendizagem } & Apresentação & - agenda de atividades com cronograma. \\
\hline & Aulas síncronas & - link para acesso às aulas interativas on-line \\
\hline & Videoaulas & - videoaulas gravadas com até $10 \mathrm{~min}$. \\
\hline & Materiais & $\begin{array}{l}\text { - textos base; } \\
\text { - livros e artigos digitais; } \\
\text { - midiateca. }\end{array}$ \\
\hline & Atividades & - atividades avaliativas. \\
\hline & Fórum & - fórum de dúvidas. \\
\hline Avaliação do curso & \multicolumn{2}{|c|}{ - avaliação da experiência e nível de satisfação } \\
\hline Certificação & \multicolumn{2}{|c|}{ - espaço para emissão do certificado dos aprovados no processo avaliativo. } \\
\hline Espaço da equipe tutorial & \multicolumn{2}{|c|}{ - interação exclusiva entre professor e tutores. } \\
\hline
\end{tabular}

Fonte: elaborado pelos autores, com base na pesquisa realizada.

Os 6 cursos não possuíam pré-requisitos, possibilitando a escolha do percurso formativo desejado pelos participantes - Quadro 2. Contemplavam carga horária de 10 horas cada e ocorreram em ambiente virtual de aprendizagem da UFRB, ancorado na plataforma Moodle. Adicionalmente, contaram com a mediação pedagógica de professores formadores da UFRB, 
apoiados por uma equipe de 21 professores tutores, selecionados mediante edital para atuação no Programa com recursos próprios da UFRB.

Quadro 2 - Relação de cursos e conteúdos ofertados.

\begin{tabular}{|l|c|l|}
\hline Curso & Carga horária & Conteúdos \\
\hline Docência On-line & 10h & $\begin{array}{l}\text { Mediação pedagógica on-line. Níveis de interação on-line. } \\
\text { Avaliação da aprendizagem em cenários virtuais. Princípios } \\
\text { do Ensino On-line. Competências digitais dos professores }\end{array}$ \\
\hline $\begin{array}{l}\text { Desenho Didático On- } \\
\text { line }\end{array}$ & 10h & $\begin{array}{l}\text { Design instrucional. Arquitetura do desenho didático on- } \\
\text { line. Matriz do desenho didático. Tecnologias digitais e suas } \\
\text { potencialidades didáticas }\end{array}$ \\
\hline $\begin{array}{l}\text { Produção e Gravação de } \\
\text { Videoaulas }\end{array}$ & 10h & $\begin{array}{l}\text { Conceituação de videoaulas. Técnicas para roteirização de } \\
\text { videoaulas. Recomendações para gravação de videoaulas. } \\
\text { Aulas síncronas ao vivo. }\end{array}$ \\
\hline $\begin{array}{l}\text { Produção e Gravação de } \\
\text { Podcast }\end{array}$ & $\begin{array}{l}\text { Conceito de Podcast no contexto da educação. Elementos } \\
\text { chaves da comunicação. Recursos da voz. Gravação de } \\
\text { Podcast. }\end{array}$ \\
\hline Turma Virtual SIGAA & $\begin{array}{l}\text { Gerenciamento do plano de curso. Configurações da Turma } \\
\text { Virtual. Criação de tópicos de aulas. Cadastro de atividades: } \\
\text { fórum, chat, questionário, tarefa. Cadastro de recursos: } \\
\text { rótulo, subtópico, referências (site, livro etc.), vídeo e } \\
\text { conteúdo. }\end{array}$ \\
\hline Google Sala de Aula & $\begin{array}{l}\text { Google Sala de Aula como ferramenta de ensino. Recursos } \\
\text { do Google Sala de Aula. } \\
\text { Implementando o Google Sala de Aula na prática. }\end{array}$ \\
\hline
\end{tabular}

Fonte: elaborado pelos autores, com base na pesquisa realizada (2021).

A modelagem do design instrucional dos cursos fundamentou-se em uma proposta interativa, com atividades que estimulavam a utilização de diversas tecnologias digitais aplicadas ao processo de ensino, visando tanto à promoção da aprendizagem como, sobretudo, à experimentação pelos professores cursistas das potencialidades educativas proporcionadas pelas tecnologias utilizadas, a fim de que pudessem implementá-las em sua práxis educativa.

Nesse sentido, foi privilegiada uma ampla gama de interfaces digitais que possibilitavam canais de comunicação direta entre professores, equipe tutorial e cursistas participantes. Santos (2019, p. 111) salienta a necessidade de se considerarem as interfaces digitais "como incubadoras de textos, narrativas, enfim, de sentidos, configurando-se como espaços formativos".

As aulas síncronas constituíram-se em interface digital privilegiada de comunicação entre professores e cursistas. Cada curso implementou 2 aulas síncronas de até 60 minutos cada, possibilitando a discussão, partilha e troca de informações entre os participantes por meio dos bate-papos que se instalavam durante a transmissão. Visando favorecer aqueles que porventura não puderam participar no momento síncrono, as aulas foram gravadas e seu respectivo link disponibilizado no AVA do curso.

A trilha de aprendizagem de cada curso contemplava também videoaulas gravadas e vídeos disponíveis on-line com conteúdos correlatos aos cursos. Tais interfaces possibilitavam maior aprofundamento da temática em estudo e foi recomendado aos professores formadores dos cursos que a duração de cada videoaula gravada tivesse entre seis e dez minutos, visando manter o engajamento dos participantes na proposta formativa, conforme Guo, Kim e Robim (2014). 
As atividades avaliativas realizadas no transcorrer dos cursos privilegiaram as interfaces digitais do AVA Moodle, tais como: a Tarefa, com elaboração de textos ou postagens de links com a produção de mapa mental; podcasts; videoaulas entre outros. A interface digital do Fórum de Discussão foi amplamente utilizada como espaço interativo de coaprendizagem e construção coletiva, possibilitando a partilha das produções realizadas por todos os participantes.

A utilização de diferentes interfaces digitais como possibilidades de instrumentos avaliativos foi proposital, visto que os estudos de Dias-Trindade e Santo (2021) apontavam lacunas nas competências digitais dos professores no tocante à avaliação da aprendizagem no ensino on-line. As interfaces digitais contemplando instrumentos avaliativos com respostas abertas foram corrigidas pela equipe tutorial, mediante critérios de avaliação previamente definidos e discutidos. Ademais, as devolutivas foram realizadas pelos tutores no transcorrer das atividades do curso, possibilitando que os cursistas tivessem acesso às informações sobre como seria avaliado, bem como às devolutivas para seu próprio processo avaliativo, conforme sugerido por Kenski (2019).

A certificação dos cursos foi realizada por meio da interface digital do AVA Moodle, sendo utilizado como critério para emissão dos certificados os cursistas que alcançaram nota mínima de 60 pontos no processo avaliativo, considerando-se uma escala de 0 a 100 pontos.

No Quadro 2, observa-se os principais dados dos cursos ofertados no percurso formativo. Os 6 cursos ofertados contaram com média aritmética de 271 inscritos, representando 30,1\% dos docentes da UFRB (UFRB, 2021b); não obstante, as temáticas dos cursos terem sido elegidas tanto em função das demandas apresentadas na consulta à comunidade acadêmica (UFRB, 2020) como nas lacunas apontadas nas competências digitais dos professores (DIAS-TRINDADE; SANTO, 2021).

Tabela 1 - Dados dos cursos ofertados aos professores

\begin{tabular}{lclcc}
\hline & Inscritos & $\begin{array}{c}\text { Certificados } \\
\text { emitidos }\end{array}$ & $\begin{array}{c}\text { \% Certificados } \\
\text { emitidos }\end{array}$ & $\begin{array}{c}\text { Avaliação de } \\
\text { satisfação* }\end{array}$ \\
\hline Docência On-line & 279 & 159 & 56,9 & 8,8 \\
\hline Desenho Didático On-lint & 202 & 109 & 54,0 & 9,0 \\
\hline Prod. Grav. Videoaulas & 320 & 131 & 40,9 & 8,2 \\
\hline Prod. Grav. Podcast & 228 & 75 & 32,9 & 9,5 \\
\hline Turma Virtual SIGAA & 291 & 92 & 31,6 & 9,3 \\
\hline Google Sala de Aula & 305 & 70 & 22,9 & 9,0 \\
\hline Total & 1625 & 636 & 39,1 & 9,0 \\
\hline
\end{tabular}

Fonte: elaborado pelos autores, com base na pesquisa realizada (2021).

*avaliação atribuída pelos cursistas concluintes, considerando-se escala de 1 (mínimo) a 9 (máximo) pontos.

Verifica-se na Tabela 1 decréscimos nos percentuais de participantes que concluíram com êxito os percursos formativos dos cursos, finalizando-os com a emissão dos certificados. 0 primeiro curso ofertado, Docência On-line, contou com $56,9 \%$ de certificados emitidos; sendo que o último curso, Google Sala de Aula, alcançou apenas 22,9\%, apesar de os cursos contemplarem índice elevado de avaliação da satisfação, apresentando média aritmética de 9,0 pontos - escala de 1 a 10. 
Um dos fatores contributivos para o baixo quantitativo de inscritos foi a definição do Conselho Acadêmico (CONAC) da UFRB ao tornar facultativa a adesão dos professores ao nomeado Calendário Acadêmico Suplementar, para oferta excepcional e experimental de componentes curriculares e de atividades de ensino e de aprendizagem não presenciais, para a graduação, no período de 14 de setembro a 19 de dezembro de 2020 (BRASIL, 2020).

Notou-se que os cursos com declínio no quantitativo de participantes que concluíram com a emissão de certificados ocorreu na semana anterior ao início do semestre suplementar, exigindo dos professores disponibilidade extra de tempo para a preparação dos planos de ensino e validação nas reuniões de colegiados. O nível de finalização dos cursos foi prejudicado com a concomitância das atividades formativas e de ensino, especialmente a partir do início das atividades do semestre letivo.

$\mathrm{Na}$ Tabela 2 percebe-se as principais dificuldades registradas pelos participantes na avaliação de satisfação dos cursos, destacando-se a administração do tempo para realização das atividades propostas $(38,8 \%)$ e as dificuldades técnicas relacionadas com trabalhar com a plataforma e o acesso à internet (32,6\%), sendo que em média 37,6\% afirmaram não ter encontrado nenhuma dificuldade.

Tabela 2 - Principais dificuldades apontadas pelos participantes.

\begin{tabular}{l|c|c|c|c|c|c}
\hline Curso & Avaliação & Devolutivas & Gestão/ tempo & Motivacionais & Técnicas & S/ dificuldades \\
\hline Docência On-line & $15,4 \%$ & $9,4 \%$ & $42,3 \%$ & $9,4 \%$ & $36,2 \%$ & $28,9 \%$ \\
\hline Desenho Didático & $7,1 \%$ & $6,1 \%$ & $40,4 \%$ & $9,1 \%$ & $26,3 \%$ & $39,4 \%$ \\
\hline Prod. Grav. Videoaula & $9,3 \%$ & $10,2 \%$ & $48,1 \%$ & $28,7 \%$ & $44,4 \%$ & $23,1 \%$ \\
\hline Prod. Grav. Podcast & $0,0 \%$ & $6,5 \%$ & $41,6 \%$ & $5,2 \%$ & $40,3 \%$ & $35,1 \%$ \\
\hline Turma Virtual SIGAA & $6,5 \%$ & $4,3 \%$ & $33,7 \%$ & $2,2 \%$ & $25,0 \%$ & $47,8 \%$ \\
\hline Google Sala de Aula & $4,2 \%$ & $5,6 \%$ & $26,4 \%$ & $2,8 \%$ & $23,6 \%$ & $51,4 \%$ \\
\hline \multicolumn{1}{r|}{ Média } & $7,1 \%$ & $7,0 \%$ & $38,8 \%$ & $9,6 \%$ & $32,6 \%$ & $37,6 \%$ \\
\hline
\end{tabular}

Fonte: elaborado pelos autores, com base na pesquisa realizada (2021).

As dificuldades apontadas pelos participantes estão intrinsecamente relacionadas com o moderado nível de desenvolvimento das competências digitais dos professores, conforme apontado nos estudos de Dias-Trindade e Santo (2021); mesmo considerando que a pesquisaconsulta à comunidade acadêmica revelou que apenas $7,2 \%$ dos docentes não dispunham de internet banda larga para o desenvolvimento de atividades remotas e 9,2\% afirmavam não ter habilidades para utilizar as ferramentas de comunicação remota (UFRB, 2020).

A implementação dos percursos formativos dos cursos on-line no Programa de Formação mostrou ter alcançado os objetivos previstos. A proposta do design instrucional utilizada mostrou-se assertiva e promoveu a interação dos participantes, visando ao aprimoramento e à promoção das competências digitais dos professores nos tópicos discutidos. A concomitância de realização dos cursos, entretanto, mostrou-se um entrave para que a maior parte dos participantes concluíssem as atividades, tendo em vista que estes apresentaram dificuldades com a administração do tempo e na utilização das interfaces digitais da plataforma Moodle, utilizada no curso. 


\subsubsection{Webinários formativos}

Os webinários ou webnars se constituem em eventos realizados on-line por meio de interfaces digitais, contemplando formatos de conferências, seminários, mesa redonda, entre outros. Frequentemente possuem transmissão em tempo real, podendo ser gravados; o organizador tem a possibilidade de compartilhar conteúdos de mídia, apresentação de slides etc. Os participantes interagem por meio de bate-papos, interfaces digitais de pesquisa em tempo real e compartilhamento de downloads de arquivos entre outras possibilidades (SILVA, D'ANDREA, 2020).

No contexto dos percursos do Programa de Formação, foram contemplados webinários formativos, visando proporcionar um espaço de discussão para troca de experiências com especialistas de universidades nacionais e internacionais, incluindo tópicos, tais como: metodologia didática on-line, processos de avaliação em cenários on-line, tecnologias digitais aplicadas à educação, pesquisa-formação na cibercultura e, finalizando o semestre, práticas exitosas do Ensino On-line UFRB - Tabela 3.

Tais webinários formativos iniciaram concomitante aos percursos dos cursos on-line, com transmissão aberta para toda a comunidade, utilizando-se uma plataforma de streaming, sendo direcionado para o canal Youtube SEAD UFRB. Os participantes interagiram por meio de batepapo com perguntas e considerações para os conferencistas. As gravações de todos os webinários realizados foram disponibilizadas para consulta por meio do sítio internet do Programa de Formação, com significativo quantitativo de visualizações pós-evento (UFRB, 2021c).

\section{Tabela 3 - Dados dos Webinários Formativos}

\begin{tabular}{|c|c|c|}
\hline Webinário & Participantes & Avaliação de satisfação* \\
\hline Metodologia didática on-line & 679 & 8,5 \\
\hline Processos de avaliação da em cenários on-line & 496 & 9,5 \\
\hline Tecnologias digitais aplicadas à educação & 456 & 9,1 \\
\hline Caminhos ubíquos: pesquisa-formação na cibercultura & 288 & 9,4 \\
\hline Práticas exitosas do Ensino On-line UFRB & 181 & 9,6 \\
\hline Média & 420 & 9,2 \\
\hline
\end{tabular}

Fonte: elaborado pelos autores, com base na pesquisa realizada (2021).

*avaliação atribuída pelos participantes, considerando-se escala de 1 (mínimo) a 9 (máximo) pontos.

Conforme evidenciado na média de 9,2 pontos relativa à avaliação da satisfação atribuída pelos participantes, os webinários alcançaram os objetivos propostos ao discutirem aspectos pertinentes da formação docente para as tecnologias digitais -Tabela 2. Foi alcançado um público total de 2.100 participantes nas transmissões ao vivo, sendo $76,9 \%$ da comunidade UFRB e os demais de instituições de ensino pública e privada de diferentes regiões do Brasil, além de participantes de Angola e Moçambique.

Os webinários formativos foram muito exitosos e contribuíram para que os professores pudessem refletir sobre suas práticas educativas. Como bem expressou um participante, tratouse de "importante iniciativa para que possamos executar as atividades de docência remota com qualidade e segurança” (Web1 -participante 92). 


\subsection{Lições aprendidas}

A avaliação constante das estratégias e das atividades realizadas em cursos on-line deve ser capaz de retroalimentar todo o processo de produção desses cursos com vistas à melhoria contínua, seja durante a realização do curso, seja após a sua conclusão, contribuindo na adequação para a oferta de novas turmas, aponta Kenski (2019).

Dessa forma, a avaliação processual norteou a implementação das atividades planejadas nos percursos formativos do Programa de Formação em Tecnologias Digitais para a Comunidade UFRB, fornecendo subsídios para a revisão das estratégias por parte dos professores e da equipe tutorial. Por exemplo, quando se percebeu nos comentários dos Fóruns o elevado nível de dificuldades dos participantes em utilizar as interfaces digitais propostas no curso Produção e Gravação de Videoulas, prontamente foi providenciada a realização de oficinas práticas, para suprir as lacunas apontadas pelos participantes. Isso possibilitou a revisão dos conteúdos desse curso, com intuito de ofertá-lo a uma nova turma, visto que, mesmo após a intervenção, quase a metade dos participantes $(44,4 \%)$ relataram dificuldades técnicas em se trabalhar com a plataforma - Quadro 3.

O percurso formativo do Programa foi realizado de forma intensiva, durante os meses de agosto e setembro de 2020, isto é, no transcorrer das quatro semanas que antecederam ao início do semestre do calendário suplementar da UFRB, impondo um cronograma inicial de dois cursos simultâneos a fim de fornecer aos docentes a formação mínima para o início das atividades online. Adicionalmente, nesse mesmo período, foram realizados os webinários formativos, sobrecarregando os participantes.

Essa estratégia de oferta intensiva deixou os participantes assoberbados com muitos quefazeres, coincidindo com o período de planejamento de seus componentes curriculares e respectiva validação nos órgãos colegiados. Deveras, nos primeiros cursos ofertados, observouse que mais de $40 \%$ dos participantes assinalaram dificuldades com a gestão do tempo - Quadro 3 -, conforme comentários registrados nos Fóruns de discussões dos cursos.

Diante disso, a equipe multidisciplinar responsável pelo design instrucional e operacionalização dos cursos considerou oportuno revisar para as próximas turmas o sequenciamento de oferta dos cursos, a fim de que sejam realizados em períodos distintos, evitando-se a concomitância das atividades no processo formativo. Isso possibilitará que um quantitativo maior de participantes conclua o percurso com certificação, visto que $39,1 \%$ dos inscritos realizaram as atividades propostas e obtiveram o certificado - Tabela 1.

\section{CONSIDERAÇÕES FINAIS}

A crise sanitária decorrente da pandemia da COVID-19 praticamente arremessou, para os ambientes virtuais de aprendizagem, as instituições de ensino e seus respectivos professores e estudantes em todo o globo, exigindo a implementação tempestiva e, por vezes, aligeirada, de programas de formação docente para o desenvolvimento das competências digitais dos professores. 
No contexto da Universidade Federal do Recôncavo da Bahia (UFRB), foi concebido e implementado um Programa de Formação em Tecnologias Digitais para a Comunidade UFRB, com percursos formativos compostos de cursos e webinários capazes de fornecer "a régua e o compasso", como diz o ditado popular, para a atuação docente nos componentes curriculares ofertados no Ensino On-line.

O Programa de Formação elaborado pela equipe multidisciplinar foi concebido com base na análise do ambiente interno e em pesquisas realizadas que demonstravam nível mediano das competências digitais dos professores da UFRB. Os cursos contaram em média com $30,1 \%$ dos docentes da UFRB, sendo que $39,1 \%$ dos inscritos concluíram as atividades até a certificação, atribuindo em média 9,0 pontos na avaliação da satisfação.

Os webinários formativos ocorreram de modo concomitante aos percursos formativos dos cursos on-line e proporcionaram um espaço complementar de discussão para a troca de experiências com especialistas. Nos webinários, foi alcançado um público total de 2.100 inscrições nas transmissões ao vivo, ultrapassando os muros virtuais da universidade ao contemplarem tanto a comunidade da UFRB como as de outras instituições de ensino de diferentes regiões do Brasil, além de participantes de Angola e Moçambique, com média de 9,2 pontos relativos à avaliação da satisfação, atribuída pelos próprios.

Como lições aprendidas, verifica-se a necessidade de revisão do sequenciamento no cronograma de oferta das próximas turmas a fim de se evitar cursos em períodos simultâneos e não sobrecarregar os docentes participantes com as atividades formativas. Da mesma forma, é oportuno que o programa formativo seja realizado de forma contínua, com atividades realizadas no transcorrer do ano todo e não meramente concentradas pouco antes do início do semestre.

Com os impactos negativos da diminuição do orçamento anual das universidades públicas, inviabilizando a seleção e contratação de tutores para a atuação em programas de formação, veio o desafio de remodelar o design instrucional dos percursos formativos para um modelo de design fechado, quando pertinente, e, sobretudo, sem prejudicar o processo formativo no necessário desenvolvimento e aprimoramento das competências digitais dos professores.

\section{REFERÊNCIAS}

BAUMAN, Z. Modernidade líquida. Rio de Janeiro: Jorge Zahar, 2001.

BRASIL. Ministério da Educação. Instituto Nacional de Estudos e Pesquisas Educacionais Anísio Teixeira. Instrumento de Avaliação de cursos de graduação presencial e a distância: Autorização. Brasília: MEC/INEP, 2017a. Disponível em: https://download.inep.gov.br/educacao_superior/avaliacao_cursos_graduacao/instrumentos/2017/curs o_autorizacao.pdf. Acesso em: 12 jan. 2021.

BRASIL. Ministério da Educação. Instituto Nacional de Estudos e Pesquisas Educacionais Anísio Teixeira. Instrumento de Avaliação de cursos de graduação presencial e a distância: Reconhecimento e renovação de reconhecimento. Brasília: MEC/INEP, 2017b. Disponível em: https://download.inep.gov.br/educacao_superior/avaliacao_cursos_graduacao/instrumentos/2017/curs o_reconhecimento.pdf. Acesso em: 12 jan. 2021. 
BRASIL. Ministério da Educação. Universidade Federal do Recôncavo da Bahia. Conselho Acadêmico. Resolução n. 19/2020. Dispõe sobre a regulamentação de Calendário Acadêmico Suplementar para oferta excepcional e experimental de componentes curriculares e de atividades de ensino e de aprendizagem não presenciais, para a graduação, no período de 14 de setembro a 19 de dezembro de 2020. Cruz das Almas: UFRB, 2020. Disponível em: https://www.ufrb.edu.br/prograd/calendarioacademico?download=1526:calendario-academico-suplementar-resolucao-n-192020\#: :text=RESOLU\%C3\%87\%C3\%830\%20N\%C2\%B0\%20019\%2F2020,19\%20de\%20dezembro\%20de \%202020. Acesso em: 13 jan. 2021.

CARDOSO, A. L. et al. Modelo pedagógico virtual UFRB: por uma educação aberta e digital. Cruz das Almas: UFRB, 2018. Disponível em: https://www2.ufrb.edu.br/ead/images/Modelo_Pedagogico.pdf. Acesso em: 13 jan. 2021.

CARDOSO, A. L.; SANTO, E. E. Literacia digital: um mosaico de experiências no contexto da formação docente. In: DIAS-TRINDADE, S.; MOREIRA, J. A.; FERREIRA, A. G. Pedagogias Digitais no Ensino Superior. Coimbra: CINEP/IPC, 2020. Disponivel em: https://www.cinep.ipc.pt/attachments/article/186/pedagogiasdigitais-no-ensino-superior-web.pdf. Acesso em: 12 jan. 2021.

CENTRO REGIONAL DE ESTUDOS PARA O DESENVOLVIMENTO DA SOCIEDADE DA INFORMAÇÃO (CETIC.BR). TIC Domicílios 2019. 2020. Disponível em: https://cetic.br/pesquisa/domicilios/indicadores/. Acesso em: 14 jan. 2021.

DIAS-TRINDADE, S.; SANTO, E. E. Competências digitais de docentes universitários em tempos de pandemia: análise da autoavaliação DigCompEdu. Revista Práxis Educacional, Vitória da Conquista, $n$. 44, p. 1-22, 2021. Disponível em: https://periodicos2.uesb.br/index.php/praxis/article/view/8336. Acesso em: 18 jan. 2021.

DIAS-TRINDADE, S.; MOREIRA, J. A.; FERREIRA, A. G. Assessment of university teachers on their digital competences. QWERTY, Open and Interdisciplinary Journal of Technology, Culture and Education, $v$. 15, n. 1, p. 50-69, 2020. Disponível em:

http://www.ckbg.org/qwerty/index.php/qwerty/article/view/341/296. Acesso em: 15 jan. 2021.

FREIRE, P. Para a revista Terra Nuova. Acervo Paulo Freire, p. 1-8, 6 de maio 1989. Disponível em: https://bit.ly/3qDG1rs. Acesso em: 18 jan. 2021.

FREIRE. P. Pedagogia da autonomia: saberes necessários à prática educativa. 31. ed. São Paulo: Paz e Terra, 1996.

GUO, P. J.; KIM, J.; ROBIN, R. How video production affects student engagement: an empirical study of MOOC Videos. Proceedings of the 1st ACM Conference on Learning at Scale Conference, Atlanta, GA, USA, p. 41-50, 4-5 March 2014. Disponível em: https://doi.org/10.1145/2556325.2566239. Acesso em: 24 jan. 2021.

HARARI, Y. N. 21 lições para o século 21. São Paulo: Companhia das Letras, 2018.

INSTITUTO PENÍNSULA. Sentimento e percepção dos professores brasileiros nos diferentes estágios do Coronavírus no Brasil: estágio intermediário - maio de 2020. 2020. Disponível em: https://www.institutopeninsula.org.br/wpcontent/uploads/2020/05/Covid19_InstitutoPeninsula_Fase2_at\%C3\%A91405-1.pdf. Acesso em: 19 jan. 2021.

KENSKI, V. M. (Org.). Design instrucional para cursos online. 2. ed. São Paulo: Artesanato Educacional, 2019. 
MINAYO, M. C. S. 0 desafio do conhecimento: pesquisa qualitativa em saúde. 9. ed. São Paulo: HUCITEC, 2006.

KOEHLER, M. J.; MISHRA, P.; CAIN, W. What is Technological Pedagogical Content Knowledge (TPACK)?. Journal of Education, n. 193, v. 3, p. 13-19, Oct. 2013. Disponível em: https://doi.org/10.1177/002205741319300303. Acesso em: 12 jan. 2021.

OBSERVATÓRIO DO PLANO NACIONAL DE EDUCAÇÃO (OPNE). Meta 15: Formação de Professores 2019. 2020. Disponível em: https://observatoriodopne.org.br/meta/formacao-de-professores. Acesso em: 19 jan. 2021.

OTA, M. A.; DIAS-TRINDADE, S. Ambientes digitais de aprendizagem e competências digitais: conhecer o presente para agir num futuro pós-COVID. Revista Interfaces Científicas: Educação, Aracaju, v. 10, n. 1, p. 211-226, 2020. Disponível em: https://doi.org/10.17564/2316-3828.2020v10n1p211-226. Acesso em: 15 jan. 2021.

PESCE, L. Políticas de formação inicial de professores, tecnologias e a construção social do tempo. Eccos: Revista Científica, São Paulo, n. 33, p. 157-172, jan./abr. 2014. Disponível em: https://www.redalyc.org/pdf/715/71531141010.pdf. Acesso em: 18 jan. 2021.

PRENSKY, M. Digital natives, digital immigrants Part 1. On the Horizon, v. 9, n. 5, p. 1-6, 2001. Disponível em: https://www.emerald.com/insight/content/doi/10.1108/10748120110424816/full/html. Acesso em: 18 jan. 2021.

PRENSKY, M. From Digital natives to digital wisdom: hopeful essays for 21st century learning. Thousand Oaks: Corwin Press, 2012. Disponível em: https://www.doi.org/10.4135/9781483387765. Acesso em: 10 jan. 2021.

ROLANDO, L.G.R.; LUZ, M. R. M. P.; SALVADOR, D. F. O conhecimento tecnológico pedagógico do conteúdo no contexto lusófono: uma revisão sistemática de literatura. Revista Brasileira de Informação na Educação, Porto Alegre, v. 23, n. 3, p. 174-190, 2015. Disponível em: http://dx.doi.org/10.5753/rbie.2015.23.03.174. Acesso em: 15 jan. 2021.

SALES, M. V.; MOREIRA, J. A. Cartografia conceitual de competência e competência digital: uma compreensão ampliada. Revista UFG, Goiânia, v. 19, p, 1-31, e-63438, ago. 2019. Disponível em: https://www.revistas.ufg.br/revistaufg/article/view/65122/35310. Acesso em: 20 jan. 2021.

SALLES, J. C. Universidade pública e democracia. São Paulo: Boitempo, 2020.

SANTOS, B. S. A Cruel Pedagogia do Vírus. Coimbra: Edições Almedina, 2020.

SANTOS, E. Pesquisa-formação na cibercultura. Teresina: EDUFPI, 2019.

SANTO, E. E.; LIMA, T. P. P. Formação continuada para tecnologias digitais em tempos de pandemia: percepções docentes sobre o curso Google Sala de Aula. Dialogia, São Paulo, n. 36, p. 283-297, set./dez. 2020. Disponível em: https://doi.org/10.5585/dialogia.n36.18355. Acesso em: 15 jan. 2021.

SILVA, J. S. et al. Letramento digital: desafios à formação docente. EmRede: Revista de Educação a Distância, Porto Alegre, v. 7, n. 2, p. 15-29, jul./dez. 2020. Disponível em: https://www.aunirede.org.br/revista/index.php/emrede/article/view/613. Acesso em: 19 jan. 2021.

SILVA, F. C. C.; D'ANDREA, G. S. Podcasts e webinars sobre Covid-19 na área de Ciência da Informação. A.to.Z: novas práticas em informação e conhecimento, Curitiba, v. 9, n. 2, p. 139-147, jul./dez. 2020. Disponível em: https://revistas.ufpr.br/atoz/article/view/75860. Acesso em: 25 jan. 2021. 
SERRES, M. Polegarzinha: uma nova forma de viver em harmonia, de pensar sobre as instituições, de ser e de saber. Rio de Janeiro: Bertrand Brasil, 2015.

TRINDADE, S. D.; MOREIRA, J. A. A emergência do mobile learning e os novos desafios formativos para a docência em rede. In: TORRES, P. L. (Org.). Redes e mídias sociais. Curitiba: Appris, 2017.

TRIVIÑOS, A. N. S. Introdução à pesquisa em Ciências Sociais: a pesquisa qualitativa em Educação. São Paulo: Atlas, 2006.

UNIVERSIDADE FEDERAL DO RECÔNCAVO DA BAHIA (UFRB). Pró-reitoria de Graduação. Consulta à comunidade acadêmica da UFRB: possibilidades de realização de atividades acadêmicas e administrativas no contexto da pandemia. Cruz das Almas: UFRB, 2020.

UNIVERSIDADE FEDERAL DO RECÔNCAVO DA BAHIA (UFRB). Pró-reitoria de Planejamento. Indicadores UFRB. Indicadores FORPLAD. Cruz das Almas: UFRB, 2021a.

UNIVERSIDADE FEDERAL DO RECÔNCAVO DA BAHIA (UFRB). Pró-reitoria de Gestão de Pessoal. Sistema Integrado de Gestão de Recursos Humanos. Docentes efetivos do magistério superior por titulação 08/2020. Cruz das Almas: UFRB, 2021b.

UNIVERSIDADE FEDERAL DO RECÔNCAVO DA BAHIA (UFRB). Superintendência de Educação Aberta e a Distância. Programa de Formação em Tecnologias Digitais. 2021c. Disponível em:

https://www2.ufrb.edu.br/ead/formacao-tecnologias-digitais. Acesso em: 23 jan. 2021. 